MRS Proceedings

http://journals.cambridge.org/OPL

Additional services for MRS Proceedings:

Email alerts: Click here

www.mrs.orglop

Subscriptions: Click here

Commercial reprints: Click here

Terms of use : Click here

\title{
Dramatic Effect of Temperature on Metal-oxide Nanostructures: Oxidation of Cu Films by In situ UHV-TEM
}

Guangwen Zhou and Judith C. Yang

MRS Proceedings / Volume 739 / 2002

DOI: 10.1557/PROC-739-H7.29

Link to this article: http://journals.cambridge.org/abstract S1946427400148961

How to cite this article:

Guangwen Zhou and Judith C. Yang (2002). Dramatic Effect of Temperature on Metal-oxide Nanostructures: Oxidation of $\mathrm{Cu}$ Films by In situ UHV-TEM. MRS Proceedings,739, H7.29 doi:10.1557/PROC-739-H7.29

Request Permissions : $\underline{\text { Click here }}$ 


\title{
Dramatic Effect of Temperature on Metal-oxide Nanostructures: Oxidation of Cu Films by In situ UHV-TEM
}

Guangwen Zhou and Judith C. Yang

Materials Science and Engineering Dept, University of Pittsburgh, Pittsburgh, PA 15261

\begin{abstract}
We investigated the temperature effect on the $\mathrm{Cu}_{2} \mathrm{O}$ morphology by oxidizing $\mathrm{Cu}(100)$ thin films at the temperature ranging from $350^{\circ} \mathrm{C}$ to $1000^{\circ} \mathrm{C}$. We demonstrated that dramatically different morphologies of oxide nanostructures can be achieved by modifying the oxidation temperature. Quasi-one-dimensional $\mathrm{Cu}_{2} \mathrm{O}$ structures with aspect ratios as large as 40:1 were formed at the oxidation temperature of $600^{\circ} \mathrm{C}$. The in situ observation data on the elongation of $\mathrm{Cu}_{2} \mathrm{O}$ islands agree with the energetic calculations based on the balance between surface and interface energies and the elastic stress relaxation in the three dimensional islands.
\end{abstract}

\section{INTRODUCTION}

From the standpoint of thermodynamics all of the metals exhibit a tendency to oxidize. The oxidation driving force depends on the free-energy change for oxide formation. But the morphological changes of oxides during oxidation depend on kinetics, and microstructural considerations. Visualizing the oxidation process will provide essential insights into the complex kinetics and energetics of nano-oxide formation [1,2]. Furthermore, oxidation can be viewed as a processing tool for creating self-ordered nanostructures and the understanding of exact formation process of oxide would provide the guidance to control the oxide nanostructures [3]. In situ ultra high vacuum transmission electron microscope (UHV-TEM) allows us to study the nucleation and growth processes of oxide at nanometer scale, provides a unique view of dynamic reactions, and enables us to understand and therefore manipulate surface reactions. Since $\mathrm{Cu}$ has been chosen by many investigators as a model system to understand oxidation kinetics [4-7], we chose $\mathrm{Cu}$ films as a model system to study the formation of the oxide nanostructures by in situ UHV-TEM. We have examined the dependence of island density, size distribution, morphology on the oxidation parameters, such as substrate temperature, oxygen pressure, and orientation of the substrate. The focus of this paper is the dramatic effect of temperature on the oxide morphology formed on $\mathrm{Cu}(100)$ thin films. Copper forms two thermodynamically stable oxides, $\mathrm{Cu}_{2} \mathrm{O}$ and $\mathrm{CuO}$. $\mathrm{Cu}_{2} \mathrm{O}$ is simple cubic lattice (space group pn$3 \mathrm{~m}$ ) with $4 \mathrm{Cu}$ and $2 \mathrm{O}$ atoms in its basis, and a lattice parameter of $4.22 \AA$. The $\mathrm{Cu}$ atoms form a FCC lattice and the $\mathrm{O}$ atoms form a $\mathrm{BCC}$ lattice, where each $\mathrm{O}$ atom is surrounded by a tetrahedron of $\mathrm{Cu}$ atoms. $\mathrm{CuO}$ has a monoclinic structure. $\mathrm{Cu}$ is a FCC metal with a lattice parameter of 3.6̊. For the temperatures and very low oxygen partial pressures used in our experiments, only $\mathrm{Cu}_{2} \mathrm{O}$ is expected to form [8].

\section{EXPERIMENTAL}

The microscope used in this work was a modified JEOL 200CX [9]. A UHV chamber was attached to the middle of the column, where the base pressure was less than $10^{-8}$ torr without the 
use of the cryoshroud. The microscope was operated at $100 \mathrm{KeV}$ to minimize irradiation effects. Single crystal $99.999 \%$ pure (by referring to the purity of the originally evaporated material) $700 \AA \mathrm{Cu}$ films were grown on irradiated $\mathrm{NaCl}(100)$ substrates in an UHV e-beam evaporation system where the chamber pressure was at $\sim 10^{-8}$ torr. The single crystal nature of the $\mathrm{Cu}$ films was determined by SAD in a TEM. The $\mathrm{Cu}$ films were removed from the substrate by dissolving the $\mathrm{NaCl}$ in de-ionized water. The native $\mathrm{Cu}$ oxide was removed inside the TEM by annealing the $\mathrm{Cu}$ films in methanol vapor at a pressure of $5 \times 10^{-5}$ torr and $350^{\circ} \mathrm{C}$, which reduces the copper oxides to copper [10]. Scientific grade oxygen gas of $99.999 \%$ purity can be admitted into the column of the microscope through a leak valve at a partial pressure between $5 \times 10^{-5}$ torr and 760 torr. The specially designed sample holder allows for resistive heating at temperatures between room temperature and $1000^{\circ} \mathrm{C}$.

\section{RESULTS}

We examined the $\mathrm{Cu}_{2} \mathrm{O}$ island formation on $\mathrm{Cu}(001)$ as a function of oxidation temperature in the range of $350^{\circ} \mathrm{C}$ to $1000^{\circ} \mathrm{C}$ at constant oxygen pressure of $5 \times 10^{-4}$ torr. The morphology of $\mathrm{Cu}_{2} \mathrm{O}$ islands formed at different oxidation temperatures is shown in Figure 1 (bright field TEM images). At $350^{\circ} \mathrm{C}$, only triangular geometry islands formed (Fig. 1a). The island size increased with continued oxidation, but the island shape did not change. At elevated temperatures, between $400^{\circ} \mathrm{C}$ and $550^{\circ} \mathrm{C}$, the islands exhibited a shape change from triangular to square or round-based islands as they increase in size due to the continued exposure to oxygen (Figure 1b).
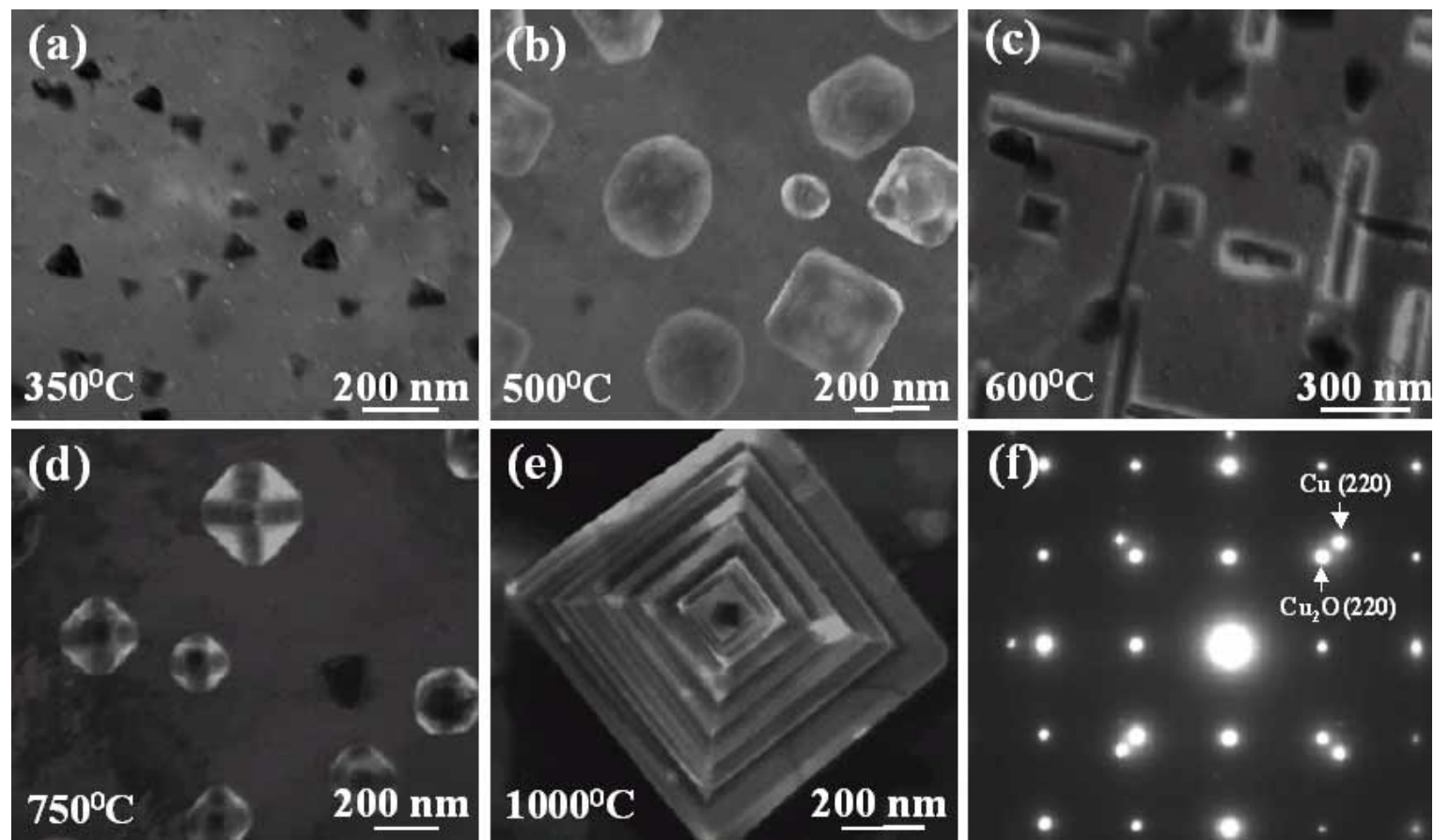

Figure 1. The morphology of $\mathrm{Cu}_{2} \mathrm{O}$ islands formed during in situ oxidation of $\mathrm{Cu}(001)$ at a oxidation partial pressure of $5 \times 10^{-4}$ torr and oxidation temperatures of (a) $350^{\circ} \mathrm{C}$, (b) $500^{\circ} \mathrm{C}$, (c) $600^{\circ} \mathrm{C}$, (d) $700^{\circ} \mathrm{C}$ and (e) $1000^{\circ} \mathrm{C}$. 

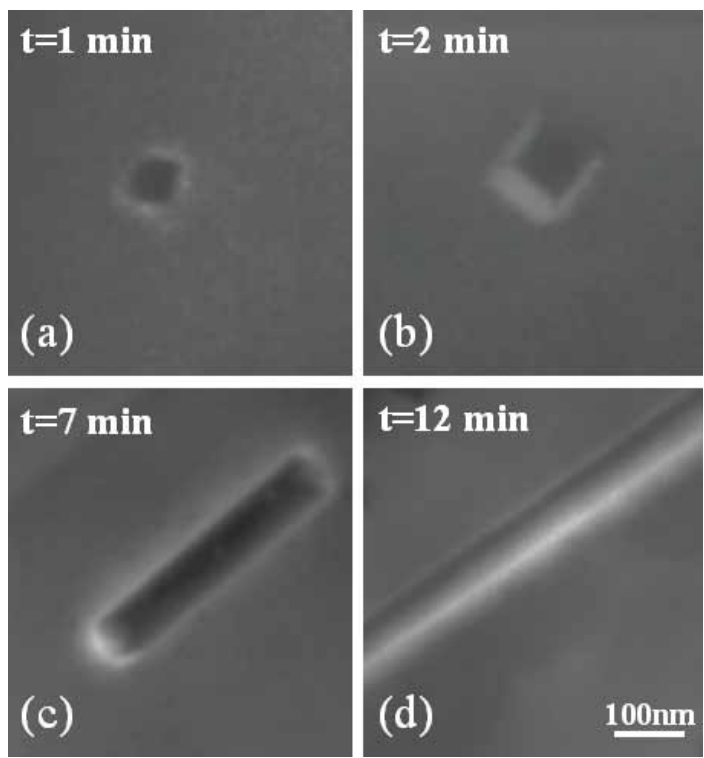

Figure 2. In situ TEM images of the four growth stages of a $\mathrm{Cu}_{2} \mathrm{O}$ island as a function of oxidation time at constant oxygen partial pressure of $1 \times 10^{-4}$ and temperature of $600^{\circ} \mathrm{C}$.

In a narrow temperature regime near $600^{\circ} \mathrm{C}$, elongated $\mathrm{Cu}_{2} \mathrm{O}$ islands formed (Fig. 1c). These islands have varying lengths, but similar widths of $\sim 110 \mathrm{~nm}$. The initial islands were square, and continued to grow uniformly, but showed a shape transition near 110nm to nanorods with continued oxidation. The elongation directions of the islands are along the two orientations, i.e., $\langle 001\rangle$ and $\langle 00 \overline{1}>$ or $\langle 010\rangle$ and $\langle 0 \overline{1} 0\rangle$, and roughly equally distributed. We have observed elongated islands with aspect ratios as large as 40:1. In order to visualize the growth of one island for a long time without interference due to coalescence with neighboring islands, we oxidized the films at oxygen pressure of $1 \times 10^{-4}$ torr. A sequence of images focusing on the growth of a single island is shown in Fig. 2. The initially formed island is square shaped (Fig. $2 \mathrm{a})$, and continues to grow uniformly (Fig. 2b), when a critical size $(\sim 110 \mathrm{~nm})$ is reached, the island shows a shape transition to nanorod (Fig. 2c, d). The contrast around the island is related to the strain in the island and the film. This was confirmed by AFM which indicates no dip around the island for the initial growth stages (Fig. 2a-c), and a very small dip $\sim 2 \mathrm{~nm}$ for the larger island (Figure 2d).

Oxidation at temperatures between $650-800^{\circ} \mathrm{C}$ resulted in the formation of pyramid islands, which have a distinctive cross-hatched pattern as shown in Figure 1d. When the $\mathrm{Cu}$ film was oxidized at temperatures between $800-1000^{\circ} \mathrm{C}$, pyramids with flat terraces formed (Figure 1e). The pyramid terraces have roughly equal width and length distribution.

For all the temperatures that we have examined, the $\mathrm{Cu}_{2} \mathrm{O}$ islands are epitaxial with $\mathrm{Cu}$ substrate as shown in Fig. 1f, i.e. $(001) \mathrm{Cu}_{2} \mathrm{O} / /(001) \mathrm{Cu}$ and $[100] \mathrm{Cu}_{2} \mathrm{O} / /[100] \mathrm{Cu}$. The SAD only confirms the crystal structure is cubic form of copper oxide (as compared to the monoclinic $\mathrm{CuO}$ ), there is the possibility of nonstoichiometry of the $\mathrm{Cu}$ oxide. EELS is the one method probe this issue, and one future work will focus on the oxidation states of the $\mathrm{Cu}$ across the interface.

The accurate estimates of the island thickness are beneficial for understanding of the formation of the nanostructured $\mathrm{Cu}_{2} \mathrm{O}$. Unfortunately the in situ UHV-TEM modifications included modifications of the sample holder such that no tilt was available. Currently, we used 
AFM for height measurements. A detailed structural characterization of the oxide islands by ex situ methods is necessary in the future work.

\section{DISCUSSION}

Many parameters affecting the kinetics and thermodynamics of growth depend sensitively on temperature, different oxide morphologies would be expected to form at various temperatures. During oxidation at low temperatures $\left(\mathrm{T}<400^{\circ} \mathrm{C}\right)$, the oxide islands adopt triangular shape, but at temperatures higher than $400^{\circ} \mathrm{C}$, the islands have a more symmetrical geometry. Only a few investigators have examined the effect of the substrate temperature on the thin film growth and morphology such as $\mathrm{Cr}$ on $\mathrm{Cu}$ substrates [11], indium-doped tin oxide films [12] and plasma enhanced chemical vapor deposition (PECVD) polycrystalline Si films [13]. Yet, only Afify et al. [12] noted a distinct change in the island morphology due to the substrate temperature, where dendritic growth was noted at higher temperatures for indium-doped tin oxide films. A possible reason why this dramatic effect of temperature on the film morphology has not been widely observed in other systems could be that the temperature ranges previously investigated were considerably smaller (only $\sim 200^{\circ} \mathrm{C}$ ) than the temperature range we examined $\left(350^{\circ} \mathrm{C}\right.$ to $1000^{\circ} \mathrm{C}$ ).

The oxide morphology is controlled by kinetic and thermodynamic factors during the oxidation. It is reasonable to expect that temperature would affect the kinetics and/or energetics of the oxide formation. The possible effects of temperature on the oxide morphology include (1) the enhanced diffusion of copper and oxygen atoms, (2) the decrease in interfacial strain due to the differences in thermal expansion coefficients, (3) the changes in mechanical properties.

Surface diffusion of oxygen plays an important role in the kinetics of the initial oxidation stage. [14] The rate of oxygen diffusion follows an Arhenius relationship with temperature. The diffusion path of oxygen is larger at higher temperature, and oxygen atoms can migrate longer distances on the surface and, hence, are more likely to be captured by the oxide islands. Therefore, the islands are more likely to form the energetically favorable configuration with increasing temperature. At higher temperatures, both oxygen and $\mathrm{Cu}$ can diffuse quickly to form more thermodynamically, equilibrium shaped oxides, such as the four-fold symmetric islands observed above $450^{\circ} \mathrm{C}$. At lower temperatures, the oxide morphology is more likely to have low symmetry due to the slower kinetics, such as the triangular shaped islands formed below $400^{\circ} \mathrm{C}$.

The formation of $\mathrm{Cu}_{2} \mathrm{O}$ islands will induce tensile stress in the $\mathrm{Cu}$ film due to the large lattice mismatch. Therefore, a strain field exists around islands, and this strain field could inhibit the island growth by creating additional activation barriers for the incorporation of atoms at island edges [15]. $\mathrm{Cu}_{2} \mathrm{O}$ has a thermal expansion coefficient of $1.9 \times 10^{-6}{ }^{\circ} \mathrm{C}^{-1}$, and $\mathrm{Cu}$ has a thermal expansion coefficient of $17 \times 10^{-6}{ }^{\circ} \mathrm{C}^{-1}$. With increasing temperature, the lattice mismatch becomes smaller, and this lattice mismatch induced strain becomes smaller too. This could explain the triangular shape at low temperatures, where the strain is high and so the interface area is minimized by the triangular shape. At higher temperatures, there is less lattice mismatch and therefore reducing interfacial strain with increasing temperatures. Hence, the chosen interfaces will be along the low energy interfaces (such as the low index planes). A third effect of temperature is on the mechanical properties of the oxide and substrate. At higher temperatures, the metal substrate and oxide become more ductile. The enhanced ductility provides a mechanical mechanism for strain relaxation affecting the oxide morphology development. 


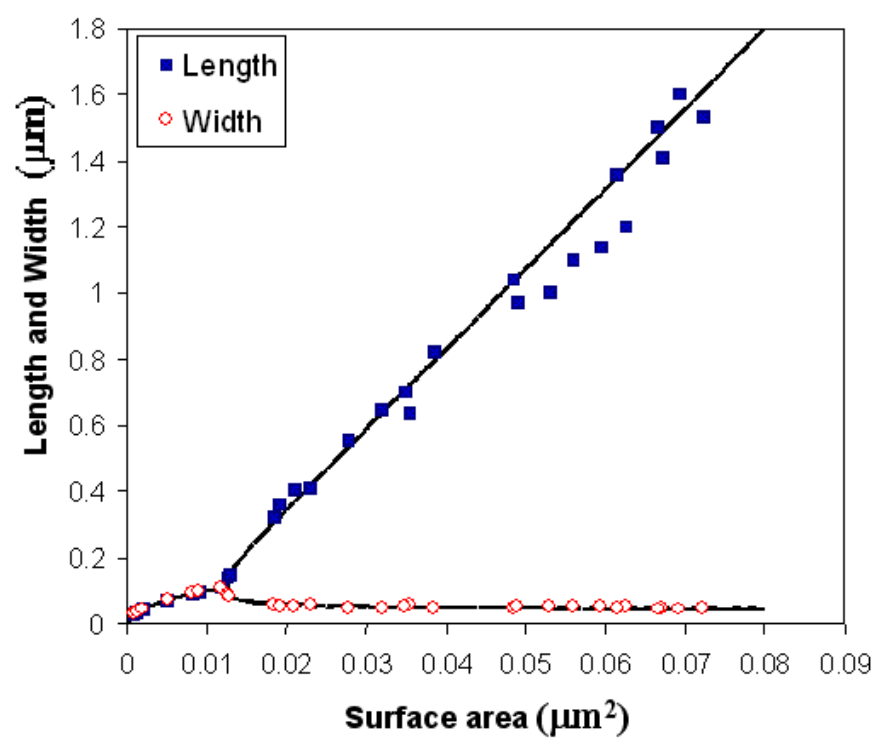

Figure 3. Dependence of both island length $t$ (squares) and width s(circles) on the island surface area. The solid lines represent a theoretical fit based on Eq.(1). The initially square shaped island undergoes a shape transition at the critical size $\mathrm{s}=\mathrm{t}=e \alpha_{0}=114 \mathrm{~nm}$. There is a reduction of the width to its optimal width, $\alpha_{0}$. The data points are obtained from the experimental results.

Particularly intriguing was the observed shape transition from square to elongated nanorods at a very narrow temperature range of $600^{\circ} \mathrm{C}$. Tersoff and Tromp have shown that strained epitaxial islands may undergo a shape transition as they grow in size [16]. Below a critical size, islands have a compact symmetric shape. However, at a larger size, they adopt a long thin shape, which has an energy minimum for the system because of the tradeoff between surface/interfacial energies and stress relaxation in the islands due to the lattice mismatch between the substrate and epitaxial film. We compared our results with this theoretical model by using the analytical expression for the energy per unit volume of a strained epitaxial island [16].

$$
\frac{E}{V}=2 \Gamma\left(\frac{1}{s}+\frac{1}{t}\right)+\frac{1}{h}\left(r_{i}+r_{t}-r_{s}\right)-2 c h\left[\frac{1}{s} \ln \left(\frac{s e^{3 / 2}}{h \cot \theta}\right)+\frac{1}{t} \ln \left(\frac{t e^{3 / 2}}{h \cot \theta}\right)\right]
$$

where $s, t$, and $h$ are the width, length, and height of the island, respectively; $\theta$ being the contact angle; $\Gamma$ contains the surface and interface energies, $\Gamma=\gamma_{e} \csc \theta-\left(\gamma_{t}+\gamma_{s}-\gamma_{i}\right) \cot \theta ; \gamma_{t}, \gamma_{s}$, and $\gamma_{e}$ are the surface energies of the island's top, the substrate, and the island's edge facet, respectively; $\gamma_{\mathrm{i}}$ is the island-substrate interface energy. $c=\sigma_{b}^{2}(1-v) / 2 \pi \mu, v$ and $\mu$ are the Possion ratio and shear modulus of the substrate, $\sigma_{\mathrm{b}}$ is the island bulk stress. The optimal balance between surface energies and strain is obtained through the minimization of the total energy expression for an island of constant height $h$ with respect to both $s$ and $t$. This gives a square island with $s=t=\alpha_{0}$, where the optimal size $\alpha_{0}$ is given by

$$
\alpha_{0}=e \phi h \exp (\Gamma / c h)
$$

where $\Phi=e^{-3 / 2} \cot \theta$. The island remains a square up to a critical size $s=t=e \alpha_{0}$. Due to continued oxidation, the island grows beyond this critical size, the square shape becomes unstable and a transition to rectangular shape takes place. As the island grows further, the aspect ratio increases.

To evaluate "c", we used standard values of $\mu_{\mathrm{Cu}}(40 \mathrm{GPa})$ and calculated $\sigma_{\mathrm{b}}$ for $\mathrm{Cu}_{2} \mathrm{O}$ from the Young's modulus $\left(30 \mathrm{GN} / \mathrm{m}^{2}\right)$ and Poisson ration $(0.455)$ of $\mathrm{Cu}_{2} \mathrm{O}$. The contact angle, $\theta=30^{\circ}$, 
and height, $h=20 \mathrm{~nm}$, were measured by the AFM. By fitting with the critical size, $e \alpha_{0}=114 \mathrm{~nm}$, we can estimate $\Gamma$ from Eqn. (2). These values are substituted into Eqn. (1) to determine the energy per unit volume as a function of width $s$ and length $t$. A comparison of Tersoff and Tromp's model with our data shows excellent agreement for the size evolution of the island as shown in Fig.3. Furthermore, we have developed a kinetic model of oxidation based on oxygen surface diffusion to the perimeter of the oxide island. We have noted an excellent agreement of volume evolution of the island with the kinetic model that validates the growth of the $\mathrm{Cu}_{2} \mathrm{O}$ islands is initially dominated by the surface diffusion of oxygen [17].

\section{CONCLUSION}

We demonstrated that oxidation temperature has a dramatic effect on the kinetics/energetics of oxide formation, which results in different morphologies of oxide nanostructures. Our in situ observation data on the elongation of $\mathrm{Cu}_{2} \mathrm{O}$ islands agree with the energetic model.

\section{ACKNOWLEDGEMENTS}

This research project is funded by NSF (\# 9902863), DOE and NACE seed grant. The experiments were performed at the MRL, UIUC, which is supported by the U.S. DOE (\#DEFG02-96-ER45439).

\section{REFERENCES}

1. N. Cabrera, N.F. Mott, Rep. Prog. Phys. 12, 163 (1948)

2. J.C. Yang, B. Kolasa, J.M. Gibson, M. Yeadon, Appl. Phys. Lett. 73, 2481 (1998)

3. S. Aggarwal, A.P. Monga, S.R. Perusse, R. Ramesh, V. Ballarotto, E.D. Williams, B.R.Chalamala, Y. Wei, R.H. Reuss, Science 287, 2235 (2000)

4. F. Young, J. Cathcart, A. Gwathmey, Acta Metall. 4, 145 (1956)

5. R.H. Milne, A. Howie, Philos. Mag. A 49, 665 (1984)

6. A. Roennquist, H. Fischmeister, J. Inst. Met. 89, 65 (1960-1961)

7. K. Heinemann, D.B. Rao, D.L Douglas, Oxid. Met. 9, 379 (1975)

8. G. Honjo, Phys. Soc. Of Japan Journal 4, 330 (1949)

9. M.L. McDonald, J.M. Gibson, F.C. Unterwald, Rev. Sci. Instrum. 60, 700 (1989)

10. S.M. Francis, F.M. Leibsle, S. Haq, N, Xiang, M. Bowker, Surf. Sci. 315, 284 (1994)

11. H. Lefakis. P.S. Ho, Thin Solid Films, 200(1), 67 (1991)

12. H.H. Afify, F.S. Terra, R.S. Momtaz, J. of Mater. Sci. 7(2), 149 (1996)

13. N.T. Tran. M.P. Keyes. Physica Status Solidi A, 126(2), 143 (1991)

14. J.C. Yang, M. Yeadon, B. Kolasa, J.M. Gibson, Scripta Materialia, 38, 1237 (1998)

15. E. Penev, P. Kratzer, M. Scheffler, Phys. Rev. B 54, 5401 (2001)

16. J. Tersoff, R.M. Tromp, Phys. Rev. Lett. 70, 2782 (1993)

17. G.W. Zhou, J. C. Yang, Phys. Rev. Lett. 89, 6101 (2002) 